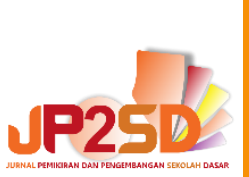

UNIVERSITAS MUHAMMADIYAH MALANG JP2SD (JURNAL PEMIKIRAN

DAN PENGEMBANGAN SEKOLAH DASAR)

http://ejournal.umm.ac.id/index.php/jp2sd

p-ISSN: 2338-1140 e-ISSN: 2527-3043

\title{
Kesadaran Nilai Pendidikan di Sekolah Dasar Ho Chi Minh Vietnam
}

\author{
Arina Restian ${ }^{\mathrm{a} 1}$, Dyah Worowirastri Ekowati ${ }^{\mathrm{b} 2}$, Erna Yayuk $^{\mathrm{c} 3}$ \\ ${ }^{a}$ Pendidikan Guru Sekolah Dasar, Universitas Muhammadiyah Malang, Indonesia \\ ${ }^{\mathrm{b}}$ Pendidikan Guru Sekolah Dasar, Universitas Muhammadiyah Malang, Indonesia \\ ${ }^{c}$ Pendidikan Guru Sekolah Dasar, Universitas Muhammadiyah Malang, Indonesia \\ 19arina.poenya@gmail.com, ${ }^{2}$ worowirastri@umm.ac.id, ${ }^{3}$ erna17@gmail.com
}

\begin{tabular}{ll}
\hline INFORMASI & ARTIKEL \\
\hline Riwayat: & 2 Maret \\
Diterima & 2020 \\
& \\
Revisi & 15 April \\
& 2020 \\
Dipublikasikan & 26 April \\
& 2020
\end{tabular}

Kata kunci:

Kesadaran, nilai pendidikan, Sekolah Dasar

\begin{abstract}
ABSTRAK
Vietnam, sebagai salah negara yang ada di Asia Tenggara dan termasuk anggota ASEAN (Association of South East Asia Nation). Negara ini mengalami banyak perkembangan di dunia pendidikan dan memberikan peningkatan nilai kehidupan dalam kurun waktu 5 tahun terakhir. Artikel ini menjelaskan "Kesadaran Nilai Pendidikan di SD Ho Chi Minh Vietnam". Oleh karenanya, untuk memenuhi data penelitian di atas, dilakukan penelitian yang menggunakan pendekatan kualitatif dan jenisnya deskripstif. Data dan sumber data yaitu Guru, Pengamat Pendidikan, Kepala Konjen RI dan beberapa staf konjen RI di Ho Chi Minh, Vietnam. Analisa data melalui proses triangulasi diperoleh hasil penelitian mengenai "Kesadaran Nilai Pendidikan di SD Ho Chi Minh Vietnam". Berdasarkan hasil observasi, wawancara dan dokumentasi diketahui bahwa nilai pendidikan yang meliputi penghargaan, kedamaian, toleransi, kasih sayang, kejujuran, kerendahan hati, kebahagiaan, kesederhanaan, kerjasama, kebebasan, tanggung jawab, persatuan tampak pada aspek kebijakan pendidikan maupun proses pendidikan yang ada di Ho Chi Minh Vietnam.
\end{abstract}

\begin{tabular}{|c|c|}
\hline & ABSTRACT \\
\hline $\begin{array}{l}\text { Keywords: } \\
\text { Awareness, education values, } \\
\text { elementary school. }\end{array}$ & $\begin{array}{l}\text { Vietnam, as one of the countries in Southeast Asia and } \\
\text { including members of the ASEAN (Association of South } \\
\text { East Asia Nations). In 2019, it has experienced many } \\
\text { develonments in the world of education and has oiven the }\end{array}$ \\
\hline 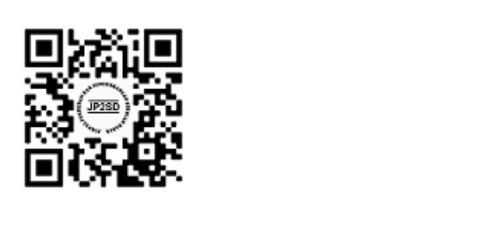 & $\begin{array}{l}\text { value of life. In this article explains " Awareness of } \\
\text { Educational Values at Ho Chi Minh Elementary School in } \\
\text { Vietnam". This research using qualitative approaches and } \\
\text { their types is descriptive. Data and data sources are } \\
\text { Teachers, Educational Observers, Head of the Indonesian }\end{array}$ \\
\hline $\begin{array}{l}\text { Copyright () 2020, Dyah } \\
\text { Worowirastri Ekowati, dkk }\end{array}$ & $\begin{array}{l}\text { Consul General and several Indonesian Consul General staff } \\
\text { in Ho Chi Minh, Vietnam. Data analysis through the } \\
\text { triangulation process obtained research results on }\end{array}$ \\
\hline
\end{tabular}


This is an open access article under the CC-BY-SA license

\begin{abstract}
"Awareness of Educational Values at Ho Chi Minh Elementary School in Vietnam". Based on observations, interviews and documentation it is known that the value of education which includes appreciation, peace, tolerance, compassion, honesty, humility, happiness, simplicity, cooperation, freedom, responsibility, unity appear in aspects of educational policy and the educational process in Ho Chi Minh Vietnam.
\end{abstract}

How to cite: Dyah Worowirastri Ekowati, dkk. (2020). Kesadaran Nilai Pendidikan di Sekolah Dasar Ho Chi Minh Vietnam. Jurnal Pemikiran dan Pengembangan Sekolah Dasar, Vol 8 No 1, 71-78. doi: https://doi.org/ 10.22219/jp2sd.v8i1.12370

\section{PENDAHULUAN}

Salah satu negara yang ada di Asia Tenggara dan termasuk anggota ASEAN (Association of South East Asia Nation) yaitu Vietnam(Dirgantoro, 2018). Negara yang memiliki populasi warganya sebanyak 84 juta jiwa ini berkembang pesat. Dengan sejumlah populasi tersebut, menempatkan negara ini sebagai negara terpadat nomor $13 \mathrm{di}$ dunia. Negara ini berada di sebelah utara china, sedangkan di barat laut berbatasan dengan Laos serta di barat daya yaitu Kamboja dan di timur yaitu Laut China Selatan. Perkembangan ekonomi negara menunjukkan grafik positif disebabkan suasana investasi yang stabil. Dengan kondisi ini daya serap pembangunan ekonomi semakin kuat. Warga negara vietnam semakin menyadari bahwa untuk mempertahankan kondisi perekonomian yang kuat memerlukan sumber daya manusia yang kuat juga.

Salah satu lini yang pelu diperkuat untuk pengembangan SDM yaitu melalui penguatan di bidang pendidikan (Dirgantoro, 2018). Mulai tahun 2007, Negara ini menggalakkan pembangunan di sektor pendidikan. Pada bidang pendidikan saat ini, Vietnam telah mengalami banyak kemajuan, termasuk dalam bidang pendidikan. Dimulai dari Sekolah Dasar, dilanjutkan pada jenjang pendidikan menengah yaitu SMP dan SMA, kemudian pada Perguruan Tinggi baik negeri maupun swasta (Mu'amar, 2018) (Yayuk \& Ekowati, 2017). Kebijakan-kebijakan yang diberlakukan oleh pemerintah Vietnam, diantaranya seperti kurikulum SD, SMP, SMA/SMK serta pendidikan tinggi. Tampak adanya pergeseran paradigma dari tahun 1986 sampai sekarang (Mu'amar, 2018). Terbuka banyak akses jaringan komunikasi antar SD, SMP, SMA/SMK serta termasuk kerjasama antar perguruan tinggi dalam dan luar Negeri. Keterbukaan ini yang kemudian menjadi banyak perubahan positif dalam bidang pendidikan (Ekowati, 2017). Tumbuhnya kesadaran nilai pendidikan dari para akademisi di dunia pendidikan. Vietnam menunjukkan kepeduliannya dalam pembangunan bidang pendidikan. Salah satu buktinya yaitu 98\% warganya termasuk kategori melek huruf (Herman et al., 2019) (Al Adawiyah, 2018). Dalam prosesnya pada tahun 2019 ini telah mengalami banyak perkembangan di dunia pendidikan dan memberikan peningkatan nilai kehidupan.

Setiap pendidik dapat merefleksikan dan menggali nilai pribadi siswa, dalam rangka pondasi untuk menciptakan suasana belajar yang berbasis nilai (Yaqin \& AS, 2018). Hal ini salah satu proses mendasar Living Values Education (Learning Assistance Program For Islamic School, 2009). Kesadaran nilai pendidikan memaknai bahwa nilai tidak diajarkan, melainkan ditangkap atau dirasakan (Soemantri, 2019). Siswa belajar dari contoh yang diberikan pendidiknya (Ekowati et al., 2017). Menjadi sangat penting bagi tiap pendidik agar mampu menjadi teladan dengan menyadari dan terus menghidupkan nilai pribadi siswa (Lewis, 2002). 
Kesadaran nilai dalam pendidikan akan dibahas secara mendalam pada artikel ini. Kesadaran nilai tersebut memuat nilai untuk kejujuran, kerendahan hati, kebahagiaan, penghargaan, kedamaian, toleransi, kasih sayang, kesederhanaan, kerjasama, kebebasan, tanggung jawab, persatuan (Mu'amar, 2018) (Komalasari \& Saripudin, 2018). Berdasarkan uraian di atas, oleh karenanya dalam artikel ini menjelaskan "Kesadaran Nilai Pendidikan di SD Ho Chi Minh Vietnam".

\section{METODE}

Artikel yang berjudul "Kesadaran Nilai Pendidikan di SD Ho Chi Minh Vietnam" ini menggunakan pendekatan penelitian kualitatif dan jenisnya adalah deskriptif (Nugrahani \& Hum, 2014). Penelitian ini dilaksanakan di Truong Tieu Hoc Luong Dinh Cua Primay School Ho Chi Minh Vietnam serta warga masyarakat di sekitar sekolah tersebut, tepatnya di district 3 Ho Chi Minh Vietnam. Pengumpulan data dilakukan dengan melakukan teknik observasi, wawancara dan dokumentasi (Gunawan, 2013).

Dalam penelitian ini, tim peneliti akan melakukan observasi, wawancara dan dokumentasi terkait 12 nilai dalam kesadaran nilai pendidikan, memuat nilai untuk kejujuran, kerendahan hati, kebahagiaan, penghargaan, kedamaian, toleransi, kasih sayang, kesederhanaan, kerjasama, kebebasan, tanggung jawab, persatuan (Sirate, 2017) (Komalasari et al., 2014). Adapun Data dan sumber data yaitu Guru, Pengamat Pendidikan, Kepala Konjen RI dan beberapa staf konjen RI di Ho Chi Minh. Pemilihan sumber data dilakukan secara purposis sampling (Nugrahani \& Hum, 2014). Selanjutnya dilakukan analisa data dalam penelitian. Melalui pengumpulan data yaitu observasi, dokumentasi, wawancara, selanjutnya dideskripsikan kemudian dipilah-pilah sesuai fokus penelitian (Gunawan, 2013). Setelah itu dilakukan proses analisis dalam kerangka memperoleh data yang sahih, triangulasi dan pelacakan mendalam, kemudian dideskripsikan, disimpulkan dan diberikan makna (Nugrahani \& Hum, 2014).

\section{HASIL DAN PEMBAHASAN}

Tim peneliti yang memiliki bidang keilmuan Pendidikan Guru Sekolah Dasar di Universitas Muhammadiyah Malang ini melakukan observasi, wawancara dan dokumentasi pada tanggal 23-26 Juli 2019. Adapun fokus penelitian terkait 12 kesadaran nilai pendidikan yang lebih dikenal dengan istilah Living Values Education. 12 ksadaran nilai pendidikan ini meliputi kejujuran, kerendahan hati, kebahagiaan, penghargaan, kedamaian, toleransi, kasih sayang, kesederhanaan, kerjasama, kebebasan, tanggung jawab, persatuan (Mu'amar, 2018) (Komalasari \& Saripudin, 2018). Hasil penelitian akan dideskripsikan secara mendalam sebagai berikut.

\section{Nilai kedamaian}

Nilai kedamaian memiliki definisi sesuai konteks dan kontennya. UNICEF mendefinisikan nilai kedamaian sebagai sebuah proses pengejawantahan sikap, keterampilan serta pengetahuan dan nilai-nilai yang diperlukan untuk membawa perubahan perilaku (Umar, 2018). Tidak hanya orang dewasa namun juga anak-anak serta para remaja untuk (a) pencegahan konflik dan kekerasan, (b) penyelesaian konflik serta (c) menciptakan situasi yang kondusif, baik secara interpersonal, intrapersonal, antarkelompok, tingkat lokal, regional, nasional serta internasional (Saputra, 2016). 
Pada penelitian ini, nilai kedamaian tampak pada hasil wawancara dengan beberapa guru SD di Ho Chi Minh serta pengamat pendidikan Trung Qu Yeow pada tanggal 24 Juli 2019. Hasil wawancara menyatakan bahwa nilai kedamaian diawali pada dasar pendidikan di Vietnam melalui Undang-Undang negara tersebut berkaitan dengan pemenuhan hak pendidikan bagi anak-anak. Selain itu juga, Undang-Undang tentang pemenuhan hak pendidikan anak perempuan. Selanjutnya juga Undang-Undang berkaitan anak-anak sekolah mulai usia TK sampai sekolah menengah atas. Hal ini yang kemudian menjadikan nilai kedamaian dalam menjalankan proses pendidikan. Hal ini didukung undang-undang penyandang disabilitas berkaitan dengan pemenuhan hak pendidikan siswa dengan disabilitas (Ahmad, 2018) (Purwanto, 2016). Undang-undang yang telah ditetapkan memberikam kedamaian kepada warga negara. Nilai ini yang menjadi salah satu dasar nilai kesadaran dalam pendidikan dalam hal kedamaian.

\section{Penghargaan}

Penghargaan adalah bagian penting dalam kesadaran nilai dalam pendidikan (Komalasari \& Saripudin, 2018) (Komalasari et al., 2014). Berdasarkan hasil wawancara pada tanggal 26 Juli 2019 dengan pengamat yang bernama Trung Qu Yeow ini menyampaikan bahwa, saat ini tren pendidikan di Vietnam, para siswa memiliki kecenderungan untuk memilih sekolah di sekolah internasional. Adapun maksud dan tujuannya agar nantinya dapat bersekolah di luar negeri. Apabila para siswa melanjutkan sekolah di luar negeri, maka para siswa dapat memajukan negaranya. Negara sangat menghargai kemajuan-kemajuan yang diperoleh. Nilai penghargaan dari pemerintah kepada para warga negara yang berhasil bersekolah di Luar Negeri tampak dalam sesi wawancara ini, saat pengamat pendidikan menyampaikan pengalaman kedua putranya yang berprofesi dokter di Australia dan Inggris. Penghargaan ini pula yang selanjutnya, berdasarkan hasil wawancara dietahui bahwa warga negara yang berhasil studi di Luar Negeri maka tidak wajib melaksanakan wajib militer.

\section{Kasih Sayang, Kebebasan dan Kebahagiaan}

Kebijakan pemerintah Vietnam dalam hal kesadaran nilai pendidikan yang berkaitan dengan kasih sayang, kebebasan dan kebahagiaan yaitu pada saat diberi kebebasan melanjutkan studi di dalam negeri maupun luar negeri. Melalui pelayanan yang diberikan oleh pemerintah dalam bidang pendidikan, menggerakkan negara Vietnam juga menjadi bagian negara yang memberikan pendidikan untuk semua (inklusif). Selain itu juga, dalam hal kasih sayang, warga masyarakat senantiasa diatur asupan makanannya dengan maksud untuk menjaga warganya dari obesitas. Dengan demikian, semua penyakit diharapkan dapat diminimalkan.

\section{Toleransi, Kerendahan hati, kejujuran dan Kerjasama}

Hasil observasi kepada beberapa guru berkaitan dengan teknis pembelajaran, hal paling penting yang ditentukan oleh pemerintah pusat adalah kebijakan penerapan metode pembelajaran. Metode pembelajaran menjadi bagian penting untuk menstimulus siswa dalam berkembang. Guru melaksanakan proses pembelajaran menggunakan berbasis IT.

Sebagian besar Guru mengajar menggunakan metode ceramah kepada siswa. Beberapa kerjasama dengan pihak luar, sebagaimana kegiatan yang dilakukan saat ini menjadi salah satu upaya untuk mengatasi dan meningkatkan kualitas pendidikan. Sebagaimana respon positif saat melaksanakan pembelajaran matematika dengan menggunakan budaya Indonesia. Dalam Sekolah Dasar tempat penelitian di Ho Chi Minh 
Vietnam, terbiasa dengan kebijakan penggunaan metode yang telah ditetapkan pusat. Saat menggunakan hal baru, merasa kesulitan menerapkan metode yang baru.

Di sisi lain hasil diskusi menunjukkan ide-ide yang baru dan inovatif. Dari hasil diskusi juga diperoleh kebijakan-kebijakan guna perbaikan dan peningkatan kualitas pembelajaran, pada siswa maupun manajemen sekolah. Pada individu siswa, temuan penelitian pada saat diskusi terkait pembuatan perencanaan pembelajaran. Hasil observasi, wawancara dan dokumentasi terhadap suasana akademik di SD SD diperoleh Living Values Education meliputi toleransi, kerendahan hati, kejujuran dan kerjasama (Mu;amar, 2018).

Berkaitan dengan nilai toleransi, sebagian besar warga negara Vietnam memiliki toleransi yang tinggi. Tampak pada keseharian para warga dalam menjalankan roda kehidupan. Para warga menggunakan jalan raya dengan saling menjaga toleransi. Selain itu juga tampak pada toleransi kehidupan beragama di lingkup kegiatan sekolah (Hammoudeh, 2012). Hal ini menjadi salah satu pendidikan bagi siswa yang berbeda agama dapat saling bertoleransi atas keberagaman (Halstead, 2007).

\section{Tanggung Jawab}

Nilai tanggung jawab pemerintah Vietnam bermuara dari sejarah perjalanan negara Perancis yang merupakan negara penjajah Vietnam. Sejak tahun 1800an, negara Perancis memiliki misi untuk membangun dan mengembangkan peradaban bermartabat di negara-negara yang dijajah. Pada bidang pendidikan, membangun peradaban dengan klasifikasi berikut.

a. Sekolah Dasar

Pendidikan ditempuh selama 5 tahun, setiap anak usia 6 tahun diharuskan oleh pemerintah untuk masuk SD dan ditanggung negara (Cholily, 2017). Pada setiap provinsi memiliki Sekolah Dasar Inti sejumlah 1 sekolah. Di sekolah dasar inti terdapat kelas bahasa Inggris. Siswa akan belajar bahasa Inggris dari kelas 1 dan pada tingkat akhir mendapat seleksi atau ujian kelulusan (Al Adawiyah, 2018).

b. Jenjang Sekolah Menengah Pertama

Pendidikan SMP ditempuh selama 4 tahun, untuk mencapai kelulusan untuk tingkat akhir anak-anak mengikuti ujian nasional (Herawati \& Hamdu, 2014). Para siswa SMP, terlebih dahulu harus menempuh seleksi dalam bentuk ujian nasional untuk melanjutkan studi ke SMA/SMK. Namun demikian, sejak tahun 2018 program tersebut berlaku.

c. Sekolah Menengah Atas

Pendidikan yang dilakukan selama 3 tahun, juga sama diakhiri dengan ujian nasional. Jika siswa tidak lulus, siswa tidak diizinkan mengikuti seleksi ujian masuk universitas.

d. Perguruan Tinggi

Waktu penyelesaian dilakukan 4 tahun, calon mahasiswa harus mengikuti seleksi dan diberi 3 pilihan.

Pada penjenjangan sekolah ini, pemerintah Vietnam menerapkan nilai tanggung jawab terhadap para warganya (Saputra, 2016) (Komalasari \& Saripudin, 2018). Selain itu juga nilai kerjasama yang baik antara pemerintah, sekolah tentunya juga dengan warga masyarakat dan para siswa.

Nilai tanggung jawab pemerintah Vietnam, juga tampak pada pembiasaan yang dilakukan pada warga negaranya sampai pada hal kecil. Misalkan pemberian yogurt untuk menjaga berat badan warganya. Harapan pemerintah Vietnam, warga negaranya tidak ada yang mengalami obesitas. Berbagai kelebihan dan kelemahan bidang pendidikan telah 
dilakukan oleh pemerintah Vietnam, tentunya sebagai warga negara perlu terus belajar agar kualitas pembelajaran terus meningkat (Ahmad, 2018). Hal ini karena kemajuan pendidikan suatu bangsa adalah salah satu tolok ukur kemajuan negara tersebut (Depdiknas, 2009).

\section{Persatuan}

Dalam rangka mendukung data Living Values Education di sekolah, tim peneliti juga melakukan wawancara ke Kepala Konsulat Jendral Republik Indonesia Bapak Hanif Salim di district 1 Ho Chi Minh. Memperhatikan kondisi pendidikan di Vietnam, Kepala Konsulat Jendral Republik Indonesia Bapak Hanif Salim menyampaikan bahwa kualitas pendidikan masih harus terus ditingkatkan. Output dalam pendidikan secara umum belum mampu disejajarkan dengan kualitas output pendidikan di dunia. Hal ini menunjukkan bahwa keberhasilan pendidikan perlu terus disempurnakan. Pendidikan di Vietnam sedang meningkatkan kualitas sumber daya manusia yang berkualitas tinggi. Berbagai kebijakan dilakukan, termasuk dengan bersinergi pada bidang industri, kerjsama dengan negara lainnya serta pengembangan ekonomi lokal dan internasional. Dari fakta yang diperoleh, setidaknya pemerintah Vietnam memahami bahwa nilai persatuan untuk meningkatkan kualitas negara.

Berdasarkan uraian yang sudah dipaparkan, tampak bahwa semua kesadaran nilai dalam bidang pendidikan yang terdiri atas 12 kesadaran nilai pendidikan ini meliputi kejujuran, kerendahan hati, kebahagiaan, penghargaan, kedamaian, toleransi, kasih sayang, kesederhanaan, kerjasama, kebebasan, tanggung jawab, persatuan telah berkembang dengan baik. Hal ini juga didukung dengan adanya sikap terbuka dari berbagai kalangan di Vietnam yang mampu mendukung kemajuan pendidikan ini. Hal terpenting yang kemudian perlu terus didukung adalah keberlanjutan dari nilai-nilai (Komalasari \& Saripudin, 2018). Setidaknya kesadaran warga negara menjaga dan mewujudkan nilai-nilai pendidikan juga menjadi faktor penting dalam kemajuan bidang pendidikan (Hammoudeh, 2012).

\section{SIMPULAN}

Hasil penelitian menunjukkan bahwa negara Vietnam merupakan negara berkembang. Termasuk dalam kesadaran nilai pendidikan yang meliputi nilai kejujuran, kerendahan hati, kebahagiaan, penghargaan, kedamaian, toleransi, kasih sayang, kesederhanaan, kerjasama, kebebasan, tanggung jawab, persatuan perlu untuk terus dikembangkan dan ditingkatkan. Oleh karenanya, saat ini Negara Vietnam terus meningkatkan kualitas untuk mencapai tujuan itu. Melalui peningkatan kualitas sumber daya manusia yang berkualitas tinggi. Berbagai kebijakan dilakukan, termasuk dengan bersinergi pada bidang industri, kerjsama dengan negara lainnya serta pengembangan ekonomi lokal dan internasional Kerjasama dengan pihak luar negeri menjadi salah satu upaya meningkatkan kualitas pembelajaran di sekolah. Berbagai upaya yang dilakukan oleh pemerintah pusat maupun sekolah mampu meningkatkan Kesadaran Nilai Pendidikan yang meliputi kedamaian, penghargaan, kasih sayang, toleransi, kerendahan hati, kejujuran, kerjasama, kebahagiaan, tanggung jawab, kesederhanaan, kebebasan, persatuan. 


\section{REFERENSI}

Ahmad, I. (2018). Proses pembelajaran digital dalam era revolusi industri 4.0. Direktur Jenderal Pembelajaran Dan Kemahasiswaan. Kemenristek Dikti.

Al Adawiyah, R. (2018). Efektivitas Buku Pembelajaran Budidaya Lele Pada Warga Buta Aksara di Kabupaten Probolinggo [PhD Thesis]. University of Muhammadiyah Malang.

Cholily, Y. M. (2017). Realita dan Problema Pembelajaran Bilangan Pi untuk Siswa Sekolah Dasar. Prosiding Seminar Nasional Pendidikan Matematika, 1.

Dirgantoro, K. P. S. (2018). Kompetensi guru matematika dalam mengembangkan kompetensi matematis siswa. Scholaria: Jurnal Pendidikan Dan Kebudayaan, $8(2), 157-166$.

Ekowati, D. W. (2017). Ethnomathematica: Pembelajaran Matematika Dalam Perspektif Budaya. Semnas Pendidikan Matematika UMM 2017, 163-171.

Ekowati, D. W., Kusumaningtyas, D. I., \& Sulistyani, N. (2017). Ethnomathematica dalam Pembelajaran Matematika (Pembelajaran Bilangan dengan Media Batik Madura, Tari Khas Trenggal dan Tari Khas Madura). Jurnal Pemikiran Dan Pengembangan Sekolah Dasar (JP2SD), 5(2), 716-721.

Gunawan, I. (2013). Metode penelitian kualitatif. Jakarta: Bumi Aksara.

Halstead, J. M. (2007). Islamic values: A distinctive framework for moral education? Journal of Moral Education, 36(3), 283-296.

Hammoudeh, M. M. (2012). Islamic values and management practices: Quality and transformation in the Arab world. Gower Publishing, Ltd.

Herawati, R., \& Hamdu, G. (2014). Pengembangan Asesmen Hots pada Pembelajaran Berbasis Masalah Tema Bermain Dengan Benda-Benda Di Sekitar. PEDADIDAKTIKA: Jurnal Ilmiah Pendidikan Guru Sekolah Dasar, 1(2), 151159.

Herman, M. C., Wardani, N. K., Muhabbatillah, S., \& Purwasih, J. H. G. (2019). Sekolah "Emak-Emak" untuk Buta Huruf di Kecamatan Leces Kabupaten Probolinggo. Jurnal Pendidikan Ilmu Sosial, 28(2), 11-16.

Komalasari, K., \& Saripudin, D. (2018). The Influence of Living Values EducationBased Civic Education Textbook on Students' Character Formation. International Journal of Instruction, 11(1), 395-410.

Komalasari, K., Saripudin, D., \& Masyitoh, I. S. (2014). Living values education model in learning and extracurricular activities to construct the students' character. Journal of Education and Practice, 5(7).

Nugrahani, F., \& Hum, M. (2014). Metode Penelitian Kualitatif. Solo: Cakra Books.

Saputra, W. N. E. (2016). Pendidikan Kedamaian: Peluang Penerapan Pada Pendidikan Tingkat Dasar Di Indonesia. Jurnal CARE (Children Advisory Research and Education), 3(3), 88-94.

Sirate, S. F. S. (2017). Studi Kualitatif tentang aktivitas etnomatematika dalam kehidupan masyarakat Tolaki. Lentera Pendidikan: Jurnal Ilmu Tarbiyah Dan Keguruan, 14(2), 123-136.

Soemantri, S. (2019). PBL dengan pendekatan realistic mathematic meningkatkan nilai karakter siswa berkebutuhan khusus. Math Didactic: Jurnal Pendidikan Matematika, 5(1), 1-12.

Umar, M. (2018). Pembinaan kedamaian hidup beragama melalui Optimalisasi pendidikan agama. Jurnal Ilmiah Iqra', 10(1). 
Yaqin, M. A., \& AS, A. H. (2018). Implementasi Sociopreneurship dengan Sistem Terintegrasi (E-Learning, E-Shopping, E-Crowdfunding) Berbasis Web Bootstrap dan Android di Kabupaten Probolinggo. Media Teknologi Informasi Dan Komputer [METIK], 2(2), 14-20.

Yayuk, E., \& Ekowati, D. W. (2017). Proses Pembelajaran Matematika Menggunakan Budaya Indonesia pada Lesson Study di SD Indonesia Bangkok Thailand. JINoP (Jurnal Inovasi Pemebelajaran), 3(1), 459-468.

Budi, Putu A. 2007. Pengembangan Profesionalisme Guru dalam Bidang Pembelajaran Melalui Lesson Study, Jurnal Pendidikan \& Pengajaran.

Catherine Lewis. 2004.Does Lesson Study Have a Future in the United States?. Online: sowi-online. de/journal/2004-1/lesson_lewis.htm

Depdiknas. 2005. "Rencana Strategis Departemen Pendidikan Nasional Tahun 20052009". Indonesia.

In'am, Akhsanul. 2009, Peningkatan Kualitas Pembelajaran melalui Lesson Study Berbasis Metakognisi, Jurnal Volume 12 No.1 Edisi Jan-Juni. Bandung: PT Remaja Rosdakarya.

J.M Tedjawati. 2011. Peningkatan Kompetensi Guru melalui Lesson Study Kasus di Kabupaten Bantul. Jakarta. Jurnal Vol.17 no.4.

JICA. 2009. Panduan Untuk Lesson Study Berbasis MGMP dan Lesson Study Berbasis Sekolah. Japan

Joni, T. Raka. 2005. Resureksi Pendidikan Profesional Guru. Malang: LP3 UMCakrawala

Learning Assistance Program for Islamic Schools. 2009. Materi Workshop Penguatan Kapasitas Dosen. Surabaya: Australian Government.

Lewis. 2002. Lesson Study: A Handbook of Teacher-Led Intructional. Philadelphia. PA:Research for Better Schools.

Mu'ammar, M. Arfan. 2018 Membangun Kesadaran Nilai Melalui Living Values Education. http://rumahpendidikan.id/2018/01/22/membangun-kesadaran-nilaimelalui-living-values-education-1/ diakses tanggal 1 oktober 2019

Mudyahardjo, Redja. 2001. Pengantar Pendidikan : Sebuah Studi Awal tentang Dasardasar.

Mulyasa. 2002. KBK: Konsep, Karakteristik, dan Implementasi. Pendidikan pada Umumnya dan Pendidikan di Indonesia. Jakarta: Raja Grafindo Perkasa.

Purwanto, Ngalim. 2006. Administrasi dan Supervisi Pendidikan. Bandung: PT Remaja Rosdakarya.

Sarwoto. 1998. Dasar-dasar Organisasi dan Manajemen. Jakarta: Ghalia Indonesia.Slamet Mulyana. 2007. Lesson Study (Makalah). Kuningan: LPMPJawa Barat

Slamet Hw dkk. 2010. Peningkatan Kompetensi Guru SD Melalui Lesson Study. Jurnal WARTA, Vol .13, No.1, edisi Maret.

Sudrajat, A. 2008. Lesson Study untuk Meningkatkan Proses dan Hasil Pembelajaran. http://akhmadsudrajat.wordpress.com/2008/02/22/less

Sukirman. 2006. "Peningkatan Profesional Guru melalui Lesson Study pada Diklat Lesson Study bagi Guru Berprestasi dan Pengurus MGMP MIPA SMP seIndonesia Tengah". Yogyakarta: FMIPA UNY. http://www.ktsp.diknas.co.id/ktspsd/ppt3 